\title{
Controle de qualidade da raiz de Operculina macrocarpa (Linn) Urb., Convolvulaceae
}

\author{
Daniele Carvalho Michelin, ${ }^{1}$ Suellen Cristiane Gandolfo Finati, ${ }^{1}$ \\ Luis Vitor Silva Sacramento, ${ }^{2}$ Wagner Vilegas, ${ }^{3}$ Hérida Regina Nunes Salgado ${ }^{*}$,
}

\begin{abstract}
${ }^{1}$ Faculdade de Ciências Farmacêuticas, Departamento de Fármacos e Medicamentos, Universidade Estadual Paulista "Julio de Mesquita Filho", Rodovia Araraquara-Jaú km 1, 14801-902 Araraquara-SP, Brasil

${ }^{2}$ Faculdade de Ciências Farmacêuticas, Departamento de Princípios Ativos Naturais e Toxicologia, Universidade Estadual Paulista "Julio de Mesquita Filho”, Rodovia Araraquara-Jaú km 1, 14801-902 Araraquara-SP, Brasil ${ }^{3}$ Instituto de Química, Departamento de Química Orgânica, Universidade Estadual Paulista "Julio de Mesquita
\end{abstract} Filho", Rua Francisco Degni s/n, 14800-900, Araraquara-SP, Brasil

\begin{abstract}
RESUMO: A qualidade dos fitoterápicos inclui rigoroso acompanhamento das diferentes etapas do desenvolvimento e produção destes produtos, desde a coleta do vegetal até a disponibilidade do produto final. Neste trabalho foi realizado o controle da qualidade do da raiz de Operculina macrocarpa (Linn) Urb., popularmente conhecida como batata-de-purga. Para o controle físicoquímico e microbiológico utilizaram-se metodologias farmacopeicas e não farmacopeicas. Os resultados obtidos mostraram que a raiz apresenta um teor de resina de 9,85\%. A análise microbiológica não apresentou crescimento de patógenos entre os outros testes realizados. Destacase a importância do estabelecimento de normas para o controle da qualidade para as plantas, a fim de que sejam utilizadas como fitoterápicos.
\end{abstract}

Unitermos: Controle de qualidade, Convolvulaceae, Operculina macrocarpa

\begin{abstract}
The Quality control of Operculina macrocarpa (Linn) Urb. roots (Convolvulaceae)". Considering the quality of the phytotherapic agents, it is important to point out that it includes rigorous attendance of the different steps of the development and production of these products, from the collection of the vegetable to the availability of the final product. In this work the quality control of the Operculina macrocarpa (Linn) Urb. roots, popularly known as 'batata-de-purga', was carried out. Pharmacopoeic and no pharmacopoeic methodologies were employed to physico-chemical and microbiological quality control. The obtained results showed that the roots presents a content of resin of $9,85 \%$, The microbiological analysis did not present pathogenic growth among the other accomplished tests. The work stands out the importance of the establishment of norms for the quality control for the plants, so that they are found able to be used for phytotherapic reasons.
\end{abstract}

Keywords: Convolvulaceae, Operculina macrocarpa, quality control

\section{INTRODUÇÃO}

Em se tratando do uso de plantas medicinais na terapêutica existe uma grande preocupação com a qualidade das drogas e seus derivados, a qual tem início na identificação correta da espécie, etapa não menos importante do que o seu plantio, colheita e beneficiamento. Isto se estende também no modo de preparo dos extratos vegetais e medicamentos. Diversos fatores influenciam a qualidade final da droga vegetal e dos seus derivados, tais como: variações climáticas, tipo de solo empregado no plantio, época da colheita, características genéticas da planta, condições de secagem, tempo de armazenamento, entre outros fatores.

Porém, é necessário obedecer aos parâmetros de qualidade para fins farmacêuticos, que são, em princípio, estabelecidos nas Farmacopeias e Códigos Oficiais. No caso das matérias-primas vegetais oriundas de plantas clássicas, ou seja, aquelas estudadas tanto do ponto de vista químico quanto farmacológico, existem monografias definindo critérios de identidade, de pureza e de teor de constituintes químicos. A maioria das descrições refere-se à planta e não ao fitoterápico. Esse tipo de monografia, para o produto acabado, ainda é escasso Farmacopeia Brasileira.

Operculina macrocarpa (Linn) Urb. 
(Convolvulaceae), popularmente conhecida como batatade-purga ou jalapa, comum no Nordeste brasileiro, é amplamente utilizada pela população devido à sua atividade laxante, purgativa, 'depurativa' contra moléstias da pele e no tratamento da leucorreia (Matos, 1982; Martins et al., 2000). Estudos avaliaram os efeitos de O. macrocarpa na motilidade intestinal de camundongos e os resultados mostraram que a espécie aumenta a motilidade intestinal, sugerindo que possui atividade laxante (Michelin, 2004).

Assim sendo, o objetivo desse trabalho foi avaliar qualidade da raiz de Operculina macrocarpa (Linn) Urb. uma vez que a espécie é amplamente utilizada pela população no tratamento da constipação intestinal, porém não consta nas últimas edições da Farmacopeia Brasileira (F. Bras., 1988; F. Bras, 2000).

\section{MATERIAL E MÉTODOS}

\section{Material vegetal}

As raízes de $O$. macrocarpa foram coletadas no município de Ilhéus, Estado da Bahia no mês de março de 2005. As raízes colhidas frescas foram rasuradas e submetidas à secagem em estufa com circulação forçada de ar, aquecido a $45^{\circ} \mathrm{C}$, até a estabilização dos valores de massa obtidos em balança semi-analítica. Em seguida procedeu-se à moagem de quantidades da droga rasurada em moinho de facas, e após este se utilizou um moinho de bolas.

\section{Análise macroscópica e microscópica}

A droga vegetal rasurada e também a pulverizada foram dispostas em placa de Petri e analisadas macroscopicamente.

Para análise microscópica da droga prepararamse lâminas permanentes empregando-se as técnicas de inclusão do material em historesina (Kraus \& Arduim, 1997) em amostras de $0,5 \mathrm{~cm} 3$ retiradas das raízes, as quais previamente tinham sido submetidas a um processo de reidratação em solução de glicerina e água $1: 1(\mathrm{v} / \mathrm{v})$ durante sete dias.

As secções anatômicas foram obtidas em micrótomo de rotação na espessura de $8 \mu \mathrm{m}$, sendo transferidas para gotas de água dispostas sobre lâminas de vidro, as quais permaneceram em temperatura ambiente até que estivessem secas e as secções bem aderidas às lâminas. A coloração das secções foi realizada utilizandose azul de toluidina em tampão fosfato em pH 6,8.

\section{Análise granulométrica}

Para padronizar-se a granulometria da droga pulverizada, amostras de $50 \mathrm{~g}$ foram submetidas à passagem forçada por vibração, através de tamises com abertura de malhas correspondentes a $0,074 \mathrm{~mm} ; 0,125 \mathrm{~mm} ; 0,177$ $\mathrm{mm} ; 0,250 \mathrm{~mm} ; 0,420 \mathrm{~mm}$ e o coletor, utilizando tamisador vibratório, na escala no dez do aparelho durante $30 \mathrm{~min}$. Após este processo, as frações foram retiradas dos tamises e do coletor e pesadas. Este procedimento foi repetido três vezes com três amostras distintas (F. Bras., 1988).

\section{Densidade aparente}

Para determinar-se a densidade aparente da droga pulverizada, seguiram-se as recomendações de Martins \& Sacramento (2004), onde quantidades do pó foram distribuídas uniformemente em encapsulador preenchendo totalmente 25 cápsulas de tamanho 00 . Em seguida, a massa das cápsulas cheias foi determinada e para os cálculos da densidade considerou-se a relação massa/ volume das cápsulas, descontando-se a massa das mesmas, vazias. Este procedimento foi repetido três vezes com três amostras distintas (Martins \& Sacramento, 2004).

\section{Determinação do teor de umidade}

Amostras de $1 \mathrm{~g}$ da droga vegetal pulverizada, exatamente pesadas, foram submetidas ao aquecimento em estufa a $110^{\circ} \mathrm{C}$ durante $5 \mathrm{~h}$. Em seguida determinou-se a massa das amostras e o valor expresso em porcentagem, representa a média de três determinações (F. Bras., 2000).

\section{Determinação do pH}

Foi preparada uma infusão a $1 \%$ com a droga vegetal moída de acordo com a Farmacopeia Brasileira (2000). A suspensão extrativa foi filtrada e após seu resfriamento executaram-se as leituras em peagômetro previamente calibrado. O resultado expresso representa média de três determinações.

\section{Determinação do teor de cinzas totais}

Para este procedimento, primeiramente, vários cadinhos de porcelana foram colocados em mufla a 450 ${ }^{\circ} \mathrm{C}$, durante $30 \mathrm{~min}$. Os mesmos foram resfriados em dessecador e tiveram as respectivas massas determinadas em balança analítica. Foram tomados exatamente 3,0 $\mathrm{g}$ do material vegetal pulverizado, cuja transferência para o cadinho se deu prontamente. Os mesmos foram incinerados e, posteriormente, submetidos à calcinação em mufla aquecida a $450{ }^{\circ} \mathrm{C}$ durante $2 \mathrm{~h}$. Em seguida, deixouse arrefecer em dessecador e procedeu-se à determinação da massa do conjunto. Esta operação foi repetida até a obtenção de valores de massa constantes. Calculou-se a porcentagem das cinzas totais em relação a massa da droga. A análise foi realizada em triplicata (F. Bras., 2000).

\section{Determinação do teor de cinzas insolúveis em ácido}

Os resíduos obtidos na determinação de cinzas 
totais foram fervidos durante 5 min com $25 \mathrm{~mL}$ de solução de ácido clorídrico a 7\% (p/V) em cadinhos cobertos com vidro de relógio. Em seguida o vidro de relógio foi lavado com $5 \mathrm{~mL}$ de água quente e essa água transferida para o cadinho. O resíduo insolúvel em ácido foi recolhido em papel de filtro isento de cinzas, e lavado com água quente até que o filtrado se mostrasse neutro. $\mathrm{O}$ papel de filtro contendo o resíduo foi transferido para o cadinho original, o mesmo foi seco em chapa quente e incinerado a $500{ }^{\circ} \mathrm{C}$ até peso constante. Foi então calculada a porcentagem de cinzas insolúveis em ácido em relação à droga. A análise foi realizada em triplicata (F. Bras., 2000).

\section{Prova de identificação de saponinas}

Cerca de $0,1 \mathrm{~g}$ da droga pulverizada foi transferido para um tubo de ensaio e acrescentaram-se de $10 \mathrm{~mL}$ de água destilada. O tubo foi agitado energicamente vinte vezes, deixado em repouso por 15 min e foi observada a formação de espuma (Farm. Bras., 1959).

\section{Determinação do teor de extrativos}

Cerca de $1 \mathrm{~g}$ da droga vegetal moída, exatamente pesado, foi submetido a decocção com $100 \mathrm{~mL}$ de água, durante $10 \mathrm{~min}$. Após o resfriamento, o volume foi completado para $100 \mathrm{~mL}$ em balão volumétrico. A solução foi filtrada em papel de filtro, e os primeiros $20 \mathrm{~mL}$ foram desprezados. Do restante do filtrado, foi pesada uma alíquota equivalente a $20 \mathrm{~g}$, em pesa-filtro previamente tarado, e foi evaporado até secura em banho-maria, sob agitação constante. $\mathrm{O}$ resíduo foi colocado em estufa, à $105{ }^{\circ} \mathrm{C}$ durante $3 \mathrm{~h}$, e em seguida resfriado em dessecador e pesado. O teor de extrativos foi calculado em massa percentual pela média de três determinações (WHO, 1998; Melo \& Petrovick, 2000).

\section{Análise microbiológica}

$\mathrm{Na}$ análise microbiológica foram realizados os seguintes ensaios: contagem do número total de microrganismos, pesquisa de Salmonella sp. e Escherichia coli e pesquisa de Staphylococcus aureus e Pseudomonas aeruginosa de acordo com Migliato et al. (2007).

\section{RESULTADOS E DISCUSSÃO}

$\mathrm{Na}$ análise macroscópica de $O$ macrocarpa foi observado que a cor nas superfícies das secções transversais da raiz aparece como branco-acinzentada, e para dentro do revestimento do órgão há de 3 a 8 anéis concêntricos estreitos e escuros alternados com anéis de coloração esbranquiçada. O pó apresentou-se fino e de cor castanho-clara.

$\mathrm{Na}$ análise microscópica foram encontradas esclereídes (Figura 1A, 1B e 1F), inúmeras unidades de grãos de amido simples e compostos (Figura 1C, 1D e 1E), em geral, agrupados em duas ou três e até doze unidades, além de grãos gêmeos, com fendas em forma de til, as quais são características. Foram encontradas também drusas de oxalato de cálcio (Figura 1B, 1C e 1G) e fileiras de células parenquimáticas, sendo uma delas com parede celular espessada com conteúdo fenólico. Sugere-se que esta célula seja um idioblasto resinoso (Figura 1I).

As estruturas encontradas nas secções anatômicas conferem com descrição microscópica da monografia (F. Bras., 1959), mostrando a autenticidade da amostra estudada. Relacionando os caracteres macroscópicos com os microscópicos pode-se dizer que os anéis estreitos e escuros dizem respeito às porções contendo as esclereídes, drusas e as células resinosas, nas imediações dos anéis esbranquiçados, os quais se referem ao parênquima de reserva de amido (Figura 1D e 1H).

Nas análise macro e microscópica os resultados obtidos estão de acordo com as especificações da monografia da batata-de-purga, o que indica a identidade da droga.

A moagem possibilitou reduzir mecanicamente o material vegetal a fragmentos de pequenas dimensões, preparando-o para a próxima etapa, a extração. Partículas com pequenas dimensões aumentam a área de contato entre o material sólido e o líquido extrator, tornando, desta forma, mais eficiente a extração (Sonaglio et al., 2003).

Para a raiz de $O$. macrocarpa foi utilizada a moagem em moinho de facas. A avaliação granulométrica do material moído é um parâmetro imprescindível a ser estabelecido, pois representa uma influência direta sobre a eficiência no processo extrativo. Após análise dos dados foi possível detectar um diâmetro médio das partículas de $0,250 \mathrm{~mm}$ (Tabela 1).

Tabela 1. Análises de controle de qualidade de $O$. macrocarpa (L.) Urb.

\begin{tabular}{|c|c|c|}
\hline Análise & Resultado & Especificação \\
\hline Granulometria & $0,250 \mathrm{~mm}$ & - \\
\hline Densidade aparente & $0,28 \mathrm{~g} / \mathrm{L}$ & - \\
\hline Umidade & $8,09 \%$ & $8-14 \%$ \\
\hline $\mathrm{pH}$ & 5,7 & - \\
\hline Cinzas totais & $7,82 \%$ & no máximo $14 \%$ \\
\hline $\begin{array}{l}\text { Cinzas insolúveis em } \\
\text { ácido }\end{array}$ & $0,98 \%$ & no máximo 3\% \\
\hline Identificação & positivo & positivo \\
\hline Teor de extrativos & $1,07 \%$ & - \\
\hline Teor de resina & $9,85 \%$ & no mínimo $15 \%$ \\
\hline $\begin{array}{l}\text { Contagem total de } \\
\text { microrganismos }\end{array}$ & $\begin{array}{l}\text { inferior a } 10 \\
\text { UFC/g }\end{array}$ & $\leq 10^{5} \mathrm{UFC} / \mathrm{g}$ \\
\hline $\begin{array}{l}\text { Pesquisa de Salmonella sp } \\
\text { e E.coli }\end{array}$ & ausente & ausência \\
\hline $\begin{array}{l}\text { Pesquisa de S.aureus e } P \text {. } \\
\text { aeruginosa }\end{array}$ & ausente & ausência \\
\hline
\end{tabular}


A determinação da perda por dessecação do pó da raiz de $O$. macrocarpa apresentou um valor de $8,09 \%$ quando ocorreu estabilização do processo. Esse resultado encontrado está de acordo com as especificações, uma vez que a Farmacopeia Brasileira (2000) preconiza um valor na faixa de 8 - $14 \%$ para drogas vegetais. A água residual encontrada na droga vegetal seca sugere como são suas condições de armazenamento, quando excede o limite preconizado pode acarretar na perda do material por contaminação microbiana ou degradação dos constituintes químicos.

$\mathrm{O}$ valor de $\mathrm{pH}$ do extrato da droga vegetal foi 5,7 utilizando água com $\mathrm{pH}$ de 6,25 , o que sugere a presença de substâncias ácidas no farmacógeno estudado.

Quanto à determinação do teor de cinzas totais e cinzas insolúveis em ácido, os teores encontrados foram de 7,82 e $0,98 \%$, respectivamente. A droga vegetal foi aprovada também quanto a esse parâmetro avaliado, uma vez que o preconizado na monografia da droga (Farm. Bras., 1959) é de, no máximo, $14 \%$ para cinzas totais e no máximo 3\% para cinzas insolúveis em ácido.

A determinação do teor de cinzas totais é muito importante para o controle de qualidade uma vez que o objetivo do mesmo é verificar a presença de impurezas inorgânicas não-voláteis que podem estar contaminando a droga vegetal (F. Bras., 2000; Sonaglio et al., 2003). A determinação do teor de cinzas insolúveis em ácido é preconizada para raízes uma vez que essas podem conter contaminantes como resíduos de terra e areia, que são detectados nesse ensaio (Sonaglio et al., 2003).

Com o objetivo de avaliar a quantidade de substâncias extraíveis, denominado de teor de extrativos, e de acordo com a Organização Mundial da Saúde (WHO, 1998), empregou-se a decocção em água. O rendimento encontrado foi de $1,07 \%$. No entanto, é importante levar em consideração a substância que se deseja extrair.
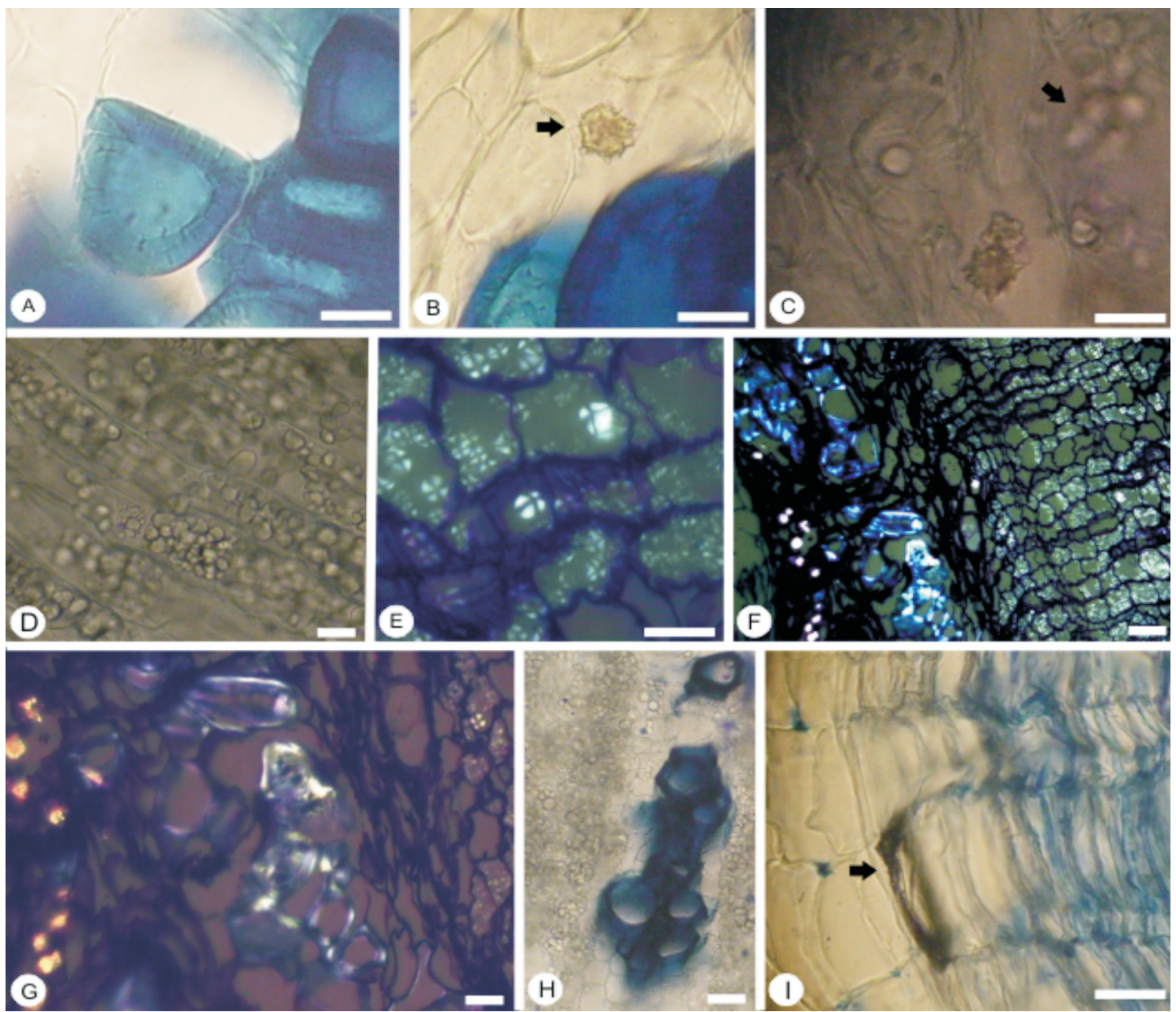

Figura 1. Características anatômicas da raiz de Operculina macrocarpa (L.) Urban. A: esclereídes com pontoações (barra: 30 $\mu$ m);

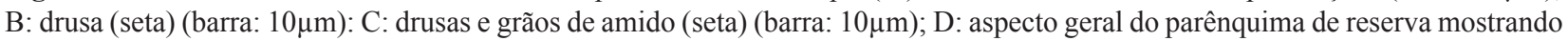
os grãos de amido poliédricos (barra: $100 \mu \mathrm{m}$ ); E: detalhe do parênquima de reserva em luz polarizada (barra: $50 \mu \mathrm{m}$ ); F e G: distribuição das drusas, das esclereídes e dos grãos de amido no tecido radicular em luz polarizada (barra: 10 $\mu \mathrm{m}$ ); H: detalhe do parênquima de reserva mostrando um dos pólos de xilema (barra: $100 \mu \mathrm{m}$ ); I: célula com depósito de fenólicos na parede celular (seta) (barra: $30 \mu \mathrm{m})$. 
Na monografia da espécie em estudo é preconizada uma prova de identificação para o grupo das saponinas, esta foi realizada e o resultado foi positivo (Tabela 1).

Considerando os diversos aspectos impostos para a garantia da qualidade do material botânico, que englobam não somente os aspectos físico-químicos, mas também o microbiológico, e considerando-se ainda, o fato dos materiais vegetais conterem um grande número de fungos e bactérias, pertencentes à sua microflora natural ou mesmo introduzidas durante a manipulação, contaminação esta que pode ser intensificada com o tempo e não somente comprometer o material em si, mas também o usuário, realizou-se o controle microbiológico da raiz de O. macrocarpa (Sonaglio et al., 2003). Os resultados do controle microbiológico e os limites permitidos são apresentados na Tabela 1, e permitiram observar que não houve crescimento microbiano de Salmonella sp., Escherichia coli, Staphylococcus aureus e Pseudomonas aeruginosa, considerados microrganismos patogênicos nas amostras analisadas, porém ocorreu crescimento de bactérias e fungos. Na contagem do número total de bactérias houve crescimento de $60 \mathrm{UFC} / \mathrm{g}$ e para fungos ocorreu o crescimento de $50 \mathrm{UFC} / \mathrm{g}$.

$\mathrm{O}$ controle microbiológico tem como função determinar o número total de microrganismos presentes em preparações não estéreis, cosméticos e drogas vegetais, além de visar a identificação dos patogênicos, tais como Salmonella sp., Escherichia coli, Staphylococcus aureus e Pseudomonas aeruginosa, que não devem estar presentes (F. Bras., 1988; WHO, 1998; Sonaglio et al., 2003).

Esta análise visa assegurar o consumo de produtos de boa qualidade; ou seja, isentos de microrganismos patogênicos ou potencialmente prejudiciais, permitindo um número limite de microrganismos aceitáveis, assegurando qualidade microbiológica da droga vegetal.

\section{CONCLUSÕES}

As metodologias empregadas foram adequadas para avaliar a qualidade da droga vegetal em estudo. Todas as análises realizadas no presente trabalho são importantes e devem ser recomendas como parâmetros seguros para o controle de qualidade da raiz de Operculina macrocarpa (Linn) Urb.

\section{AGRADECIMENTOS}

Os autores agradecem à Maria Angélica Lima Barreto e Maria de Fátima Rodrigues, pelo apoio técnico e ao CNPq, FAPESP e ao programa PADC-FCF-UNESP pelo apoio financeiro.

\section{REFERÊNCIAS}

Brown JKS 1988. Acta Amazônica, 18: 291-303.

Cechinel Filho V, Yunes RA 1998. Estratégias para a obtenção de compostos farmacologicamente ativos a partir de plantas medicinais. Conceitos sobre modificação estrutural para otimização da atividade. Quím. Nova 21: 99-105.

Farmacopéia Brasileira 1959. 2. ed. São Paulo: Siqueira.

Farmacopéia Brasileira 1988. 4.ed. São Paulo: Atheneu.

Farmacopéia Brasileira 2000. 4. ed. São Paulo: Atheneu.

Kraus JE, Arduin M 1997. Manual básico de métodos em morfologia vegetal. Rio de Janeiro: Seopédica.

Lima LR, Xavier HS, Meira JL, Neto PJR 2006. Desenvolvimento e validação da metodologia de quantificação gravimétrica de resina glicosídica em fitoterápicos contendo Operculina macrocarpa (L.) Urban. Rev Bras Farmacog 16: 562-7.

Martins ER, Castro DM, Castelani DC, Dias JE 2000. Plantas medicinais. Viçosa: UFV.

Martins AB, Sacramento LVS 2004. Análise microscópica e física para controle de qualidade primária de matéria prima vegetal pulverizada. $16^{\circ}$ Congresso de Iniciação Cientifica UNESP. Ilha Solteira, Brasil.

Matos FJA 1982. Aproveitamento de plantas medicinais da região nordeste. Rev Bras Farm 63: 132-140.

Mello JCP, Petrovick PR 2000. Quality control of Baccahris trimera (Less) DC (Asteraceae) hydroalcoholic extracts Acta Farm Bonaerense 19: 211-15.

Michelin DC, Salgado HRN 2004. Avaliação da atividade laxante de Operculina macrocarpa L. Urban (Convolvulaceae). Rev Bras Farmacog 14: 105-9.

Migliato KF, Moreira RRD, Mello JCP, Sacramento LVS, Corrêa MA, Salgado HRN 2007. Rev Bras Farmacog 17: 94101.

Sonaglio D, Ortega GG, Petrovick PR, Bassani VL 2003. Desenvolvimento tecnológico e produção e fitoterápicos. In: Simões CMO, Schenkel EP, Gosmann, Mello, JCP, Mentz LA, Petrovick PR Farmacognosia: da planta ao medicamento. 5.ed. Porto Alegre/Florianópolis: Editora da UFRGS/ Editora da UFSC, 2003.

World Health Organization 1998. Regional office for the western pacific research guidelines for evaluating the safety and efficacy of herbal medicines. Manila. 